\title{
Sustainability in extrusion-based additive manufacturing technologies
}

\author{
Dino Freitas $^{1} \cdot$ Henrique A. Almeida ${ }^{2}$ Helena Bártolo ${ }^{2}$ Paulo J. Bártolo ${ }^{1,3}$
}

Received: 7 August 2015/ Accepted: 17 March 2016/Published online: 19 April 2016

(C) Springer International Publishing Switzerland 2016

\begin{abstract}
Growing environmental and social concerns about human society's impact on the natural environment have been pushing sustainable development issues into the front line of public policies. The degradation of natural resources has been aggravated by several other factors: the actual lifestyle of consumer societies, the rapid growth of emerging countries, rising inequalities among regions, and the reduction of the life cycle time for each product requiring a high consumption of limited resources. Sustainable industrial practices can contribute to the development of more sustainable products and processes. It is critical to apply eco-design principles and develop greener products and production processes, reducing impacts associated with its production and consumption. An environmental impact assessment should be taken into account from the early design and production phases, through all the stages of a product's life until disposal. As public interest in additive manufacturing grows, its increasing usage for the production of final parts can support a drive towards more sustainable manufacturing processes. To introduce sustainability awareness during extrusion-based additive manufacturing productions, a study of the production of a part in terms its building orientation and internal filling, regarding the production time, energy
\end{abstract}

Henrique A. Almeida

henrique.almeida@ipleiria.pt

1 Manchester Biomanufacturing Centre, University of Manchester, Manchester, UK

2 School of Technology and Management, Polytechnic Institute of Leiria, Campus 2, Morro do Lena, Alto do Vieiro, Apartado 4163, 2411-901 Leiria, Portugal

3 School of Mechanical, Aerospace and Civil Engineering, University of Manchester, Manchester, UK consumption and end-of-life scenarios is considered. By combining the additive processes with eco-design, a higher awareness is possible, which results in added value to the produced parts while maintaining the part's objective performance.

Keywords Sustainable manufacturing - Additive manufacturing · Fused deposition modelling . Environmental impact $\cdot$ Eco-design

\section{Introduction}

Sustainability has become a key concern for government policies, businesses and general public. Sustainable development is a fundamental issue, involving significant challenges to minimise environmental and social impacts of human actions. The degradation of natural resources has been aggravated by several other factors like the actual lifestyle of consumer societies, the rapid growth of emerging countries, inequalities between regions, and the reduction time in the life cycle of each product requiring a high consumption of production resources. Sustainable industrial practices can contribute to the development of more sustainable products and processes $[10,25]$. It is essential to apply eco-design principles and develop more eco-friendly products and production processes. To reduce its environmental impacts, an environmental impact evaluation should be considered in all manufacturing and processing technologies, even in additive manufacturing (AM) $[30,40]$.

In general, AM processes [9] possess good environmental characteristics [31]. By utilizing only the amount of material needed for the building of the final part, these technologies have the potential to reduce the life cycle 
material mass and energy consumption when compared to conventional subtractive techniques by eliminating scrap, on top of eliminating the use of damaging further process enablers [22, 45]. On the other hand, some processes require support structures that are discarded after each part is built, which in some cases can be equivalent to the amount of part material, if the initial preparation phase isn't properly analysed or more due to the complexity of the part being produced [18].

Additive manufacturing systems have significant advantages compared with traditional ones such as the ability to closely match the trends associated with consumer demand regarding the product's lifecycle, as well the capability of product customization [18]. Consumers replace many products as a lifestyle decision more associated with trends than need. Consistent with this philosophy, manufacturing systems should be capable of responding quickly and efficiently in a sustainable way, allowing implementation of changes in products, without significant capital cost, while providing a good product customization [22].

Certain techniques also have the ability to completely eliminate supply chain operations associated with the production of new tooling, enabling the repair and remanufacturing of obsolete or failed tooling [33, 45]. A variety of industrial sectors has embraced remanufacturing of existing products, instead of original production, an effective approach to simultaneously reduce costs and environmental impacts, increasing productivity. These technologies also facilitates the elimination of environmentally polluting process enablers in the tooling industry, and repair and remanufacture valuable tools and dies, as well final products [37, 45].

Additive manufacturing machines are usually small therefore they can be easily located close to any existing market [19]. The logistics of moving parts around are consequently reduced, allowing moving raw materials in relatively small quantities around the world. On the other hand, raw materials for AM are quite common, which may lead to a possible net reduction in transportation costs [18].

Regarding the carbon footprint reduction of AM, there are five main environmental and sustainable benefits in adopting these technologies [37, 45]:

- Reduced amount of raw material required in the supply chain. Hence, reduced need to mine and process primary material ores.

- Reduced need for energy intensive and wasteful manufacturing processes, such as casting or processes like CNC machining requiring cutting fluids.

- Ability to design more efficient products with improved operational performance, such as hydraulic components with conformal fluid paths.
- Reduction in weight of transport-related products, contributing to diminish the carbon footprint.

- Parts can be manufactured closer to the point of consumption.

Along with the sustainability issues concerning the building of support structures during production, AM present two main disadvantages [18]. Additive manufacturing machines need a controlled environment without excessive heat and humidity, for both machine and raw material, and the energy used to keep this machine working effectively is negative. In addition, the energy usage for AM systems is generally unfavourable [7], as some machines need to use pre-heated and air controlled building chambers, as well the energy needed for the processing of raw materials, such as lasers.

Supporting sustainability awareness in AM production, this research work presents an environmental impact evaluation of a fused deposition modelling system and all the necessary reflections for a more ecological production of extrusion based parts.

\section{Additive manufacturing}

Additive Manufacturing is defined as: "the use of a computer aided design (CAD) based automated layer-by-layer manufacturing process to construct parts that are used directly as finished products or components" [24]. The main feature is the ability to produce parts of virtually any shape complexity is huge, as the process is capable of creating mind boggling geometries in spite of their functionality, requirements and materials [19, 24].

All existing processes require input data from a three dimensional (3D) solid CAD model, usually as slices (cross sectional data). The designer must first use a CAD software to design the product, with all the requisites for manufacturing. This model is then tessellated and exported as an STL file, which is the current industrial standard for facetted models. In some cases, supports are necessary to brace overhangs, which in this case, the system's proprietary software performs the design of the support structures. The model is then sliced and the sliced data is then sent to the additive hardware machine for the production of the final physical part $[8,19]$. The information flowchart is illustrated below in Fig. 1.

Additionally to the standard importing file, the STL file format, all AM systems share another common problem, the part's orientation during production. Orientation refers to the building direction regarding the part in which the slices are built [3, 19, 38]. Determination of the optimal part orientation is a fundamental problem in layered manufacturing [2, 19, 38], since the building direction has 


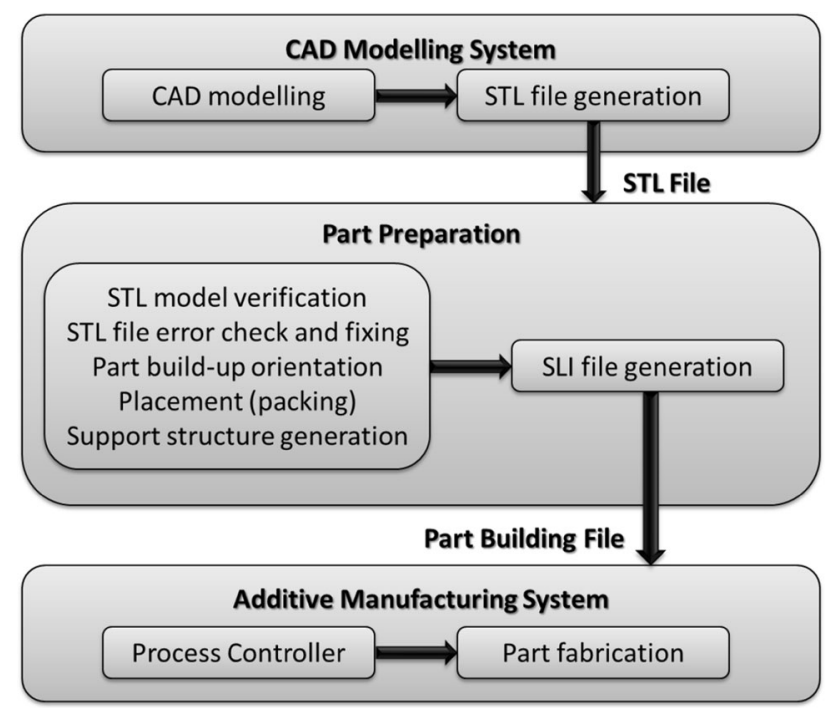

Fig. 1 Sequence of phases for obtaining models through rapid prototyping techniques (adapted from Lee [29])

a significant effect on many key characteristics which determine the final part's cost [15, 27], dimensional accuracy $[16,41-43,50]$, surface roughness $[6,34,48,49]$ and even the part's mechanical properties $[1,4,11,20,26,28$, $32,36,44]$. Selection of an optimum part's building orientation is a very important factor as it improves dimensional accuracy and surface finish and reduces building time and support structures, optimizing the final cost of the physical part [2, 12, 19, 35, 38]. Determining the optimal part orientation is a difficult and time consuming task as one has to trade-off among various contradicting objectives like part surface finish and building time [2, 12, 19, 35, 38]. An inadequate choice may result in physical models with a significant "staircase effect" resulting in parts of poor surface quality [47]. In 2013, Zhang and Bernard [51] presented a multi-attribute decision making tool in order to aid the selection of the part's orientation, where they also presented a literacy review of the methodologies that were developed since 1995. Neither the new multi-attribute decision making tool or the listed methodologies in the literacy review, mention environmental awareness as one of the key issues in the selection process for a part's orientation.

A number of process specific parameters and constraints have to be considered while making the right decisions for the fabrication of AM products [19, 23, 35]. An additional issue that needs to be addressed is the environmental impact of the several choices made during the production process of AM systems [45].

Additive manufacturing technologies include four main fabrication approaches as can be observed at Fig. 2 [19].

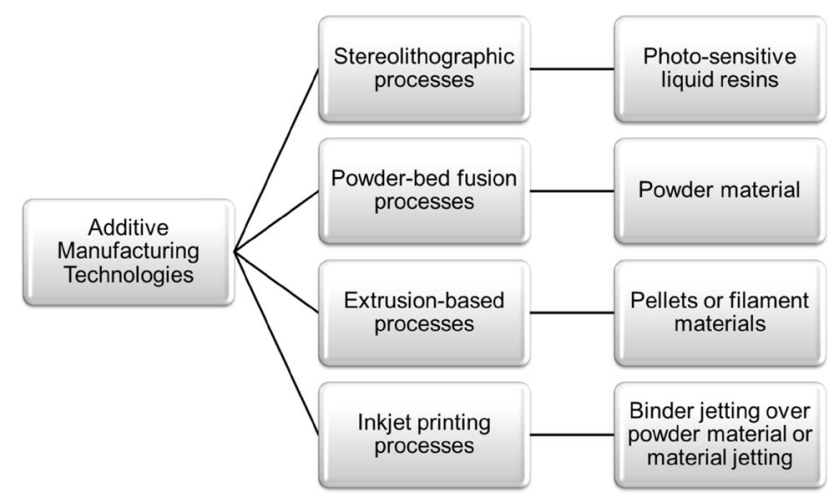

Fig. 2 Classification of AM technologies [8, 19]

\section{Fused deposition modelling}

One of the most commonly used techniques, the extrusionbased technique, commercially known as Fused Deposition Modelling (FDM), was developed by Scott Crump in 1989 [14]. Thin crystalline or amorphous thermoplastic filaments are melted by heating and guided by a robotic device controlled by a computer and by this process forming the 3D objects (see Fig. 3). The model material leaves the extruder in a liquid form and hardens immediately [19, 24]. The previously formed layer, which is the substrate for the next layer to assure good interlayer adhesion, must be maintained at a temperature just below the solidification point of the thermoplastic material. This is possible through previously heating the building chamber and maintaining its temperature during the production [13, 19]. This process comprehends several processing parameters that affect the quality and performance of the produced parts. Some of

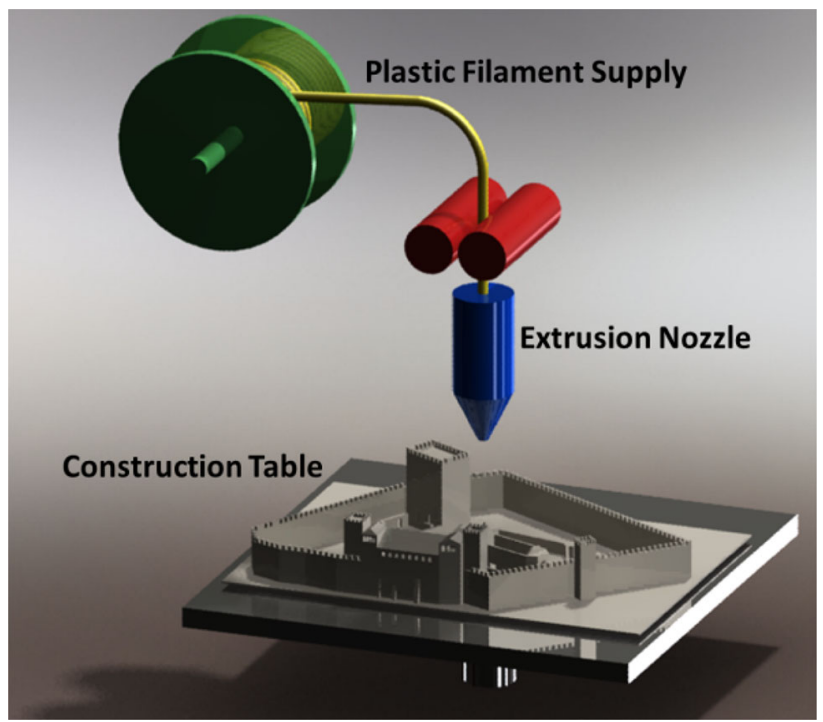

Fig. 3 Fused deposition modelling process 
these parameters are: the distance between extruded filaments, width of the filaments, layer thickness, the lay-down pattern of each layer, the thickness of the outer shell when producing low or high density parts, etc. $[4,5,16,19,26$, $43,44]$. This implies that the correct building strategy has a significant effect on both the properties and performance of the produced part.

During the production of the extruded parts, two modeller materials are dispensed through a dual tip mechanism in the extrusion head $[19,24]$. As mentioned before, a primary modeller material is used to produce the model geometry and a secondary material, or release material, is used to produce the support structures [13]. The release material forms a support structure bonding the primary material of the physical model. Currently, there are two types of release materials, namely, release materials that can be easily broken off (Break Away Support System) or simply washed away (WaterWorks Soluble Support System). Figure 4 illustrates a produced part with its support material before the removal process.
Another important aspect that should also be considered within the FDM process every time a production occurs is the type of part filling used for the interior areas of the produced parts. Three types of interior part fillings can be selected [46]:

- Solid Can be used when a stronger, more durable part is desired. Build times will be longer and more material is added (Fig. 5a);

- Sparse high density This is the default model interior style, which is highly recommended. Build times will be shorter, less material will be used. The possibility to produce curled parts, for geometries with large mass, will be greatly reduced (Fig. 5b);

- Sparse low density The interior will be "honeycombed" or "hatched". This style allows the shortest build times and lowest material usage, but will decrease the strength of the part (Fig. 5c).

In summary, the main advantages and disadvantages of the FDM process are listed in Table 1 [13, 19, 24, 35].
Fig. 4 a Imported building part before pre-processing; and b building part after preprocessing with supporting structures (part material in dark grey and support structures in light grey) (a)
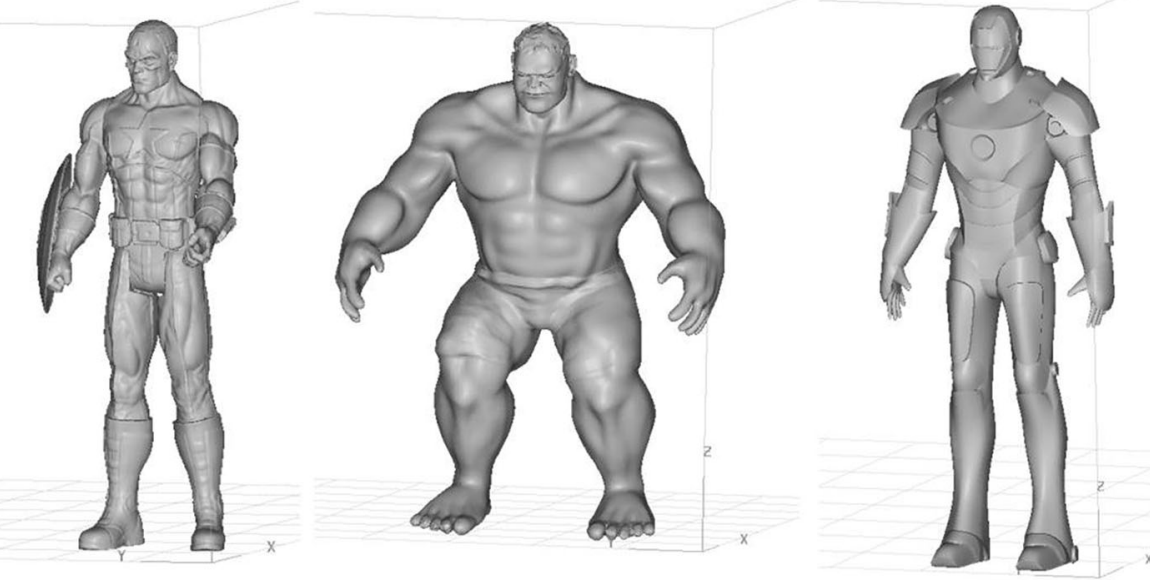

(b)
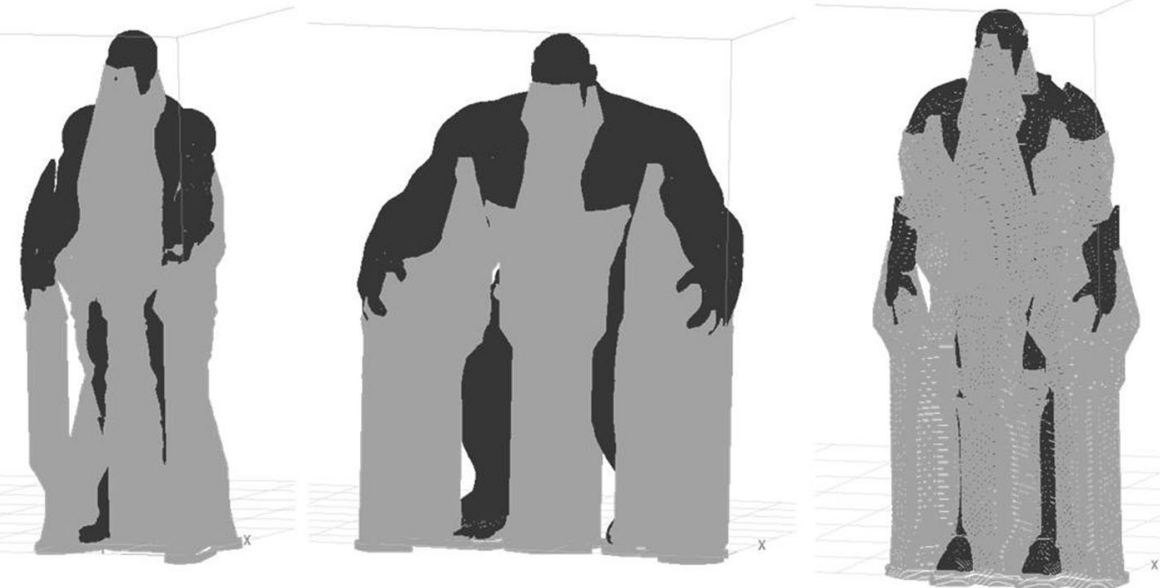
Fig. 5 a Solid, b sparse high density (HD), c sparse low density (LD) internal part filling
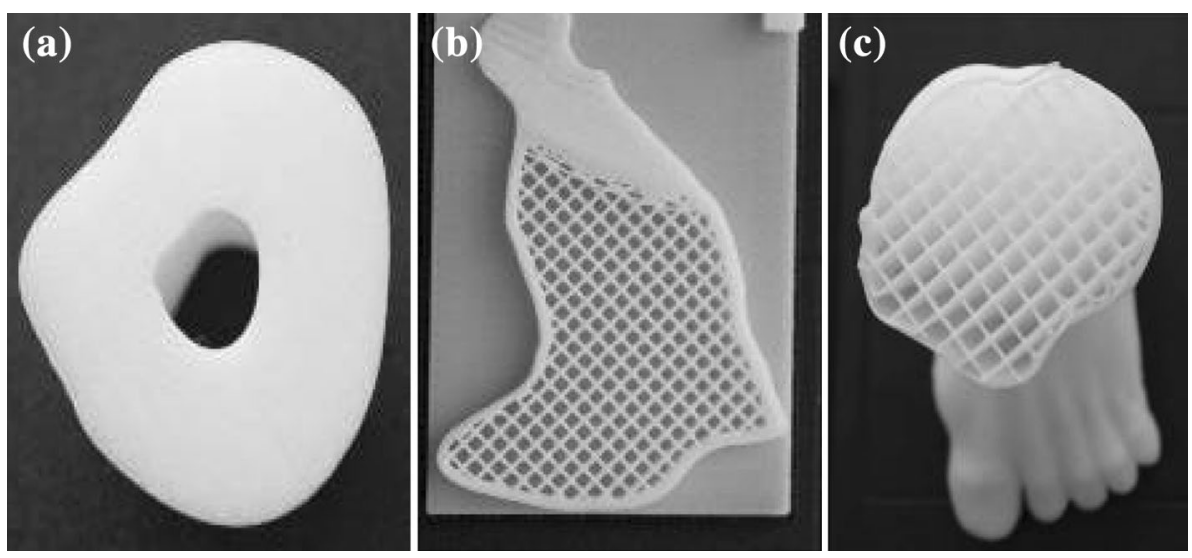

Table 1 Advantages and disadvantages of the FDM process [13, 19, 24, 35]

\begin{abstract}
Advantages
It is easy to change materials

There is a good variety of materials available

There is no exposure to toxic materials or lasers

Capable of fabricating functional parts

Additive process with minimal wastage of building material

The support material is easy to remove

Disadvantages

Support structures are required

The process is slow on models of large mass

The models have poor strength in the vertical direction

Temperature fluctuations during production can lead to delamination

Restricted accuracy due to the diameter of the building filament The process presents an unpredictable shrinkage
\end{abstract}

\section{D4E computational tool}

A computational tool called design for environment (D4E) was developed in order to perform life cycle assessment during the product development cycle [39, 40]. This tool, based on eco-design principles, can be easily adapted to all product design practices within an industrial environment. This system, developed to assist designers and users to obtain more sustainable solutions, supports design decisions at early product design stages, minimizing this way the environmental impact of products during its whole life cycle.

The D4E system uses a life cycle assessment (LCA) approach to evaluate the environmental impact of a product, supporting design decision-making, as it enables to quantify all inputs and outputs in a qualitative and quantitative way at all life cycle stages. These life-cycle phases can be described as pre-production, production, distribution, consumption and disposal [39].

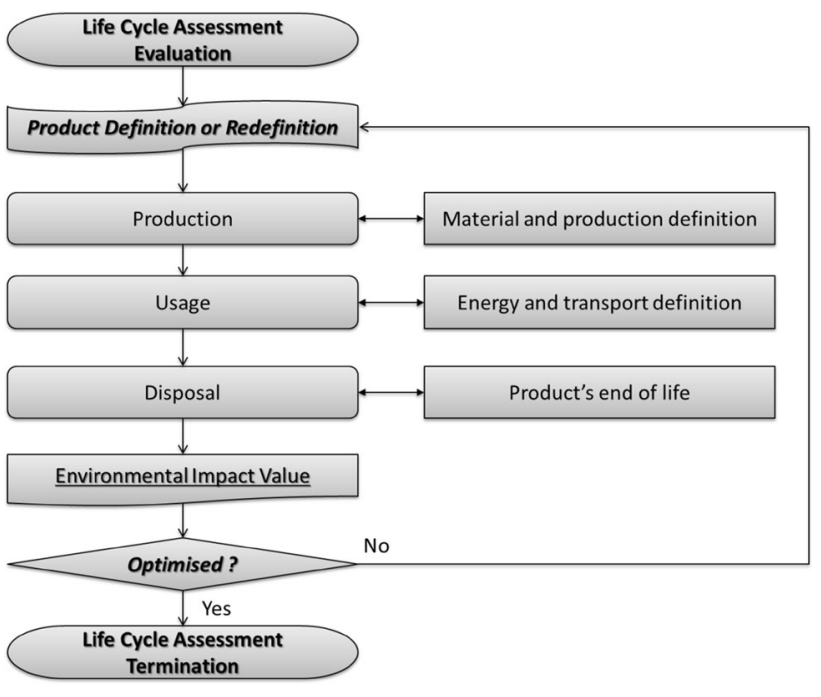

Fig. 6 Flowchart of D4E tool

This tool uses eco-indicators to quantify the environmental impact for each LCA component of a given product. These eco-indicators allow measuring the environmental impact of a material or process throughout its life cycle, considering the materials used along the manufacturing process, its energy consumption, transport and final destination [17, 21]. Figure 6 shows the D4E flowchart and it explains each step the user needs to follow in order to obtain a product's life cycle assessment.

The first window entitled life cycle identifies the project, i.e., the general information about the project is filled out; including name, date, reference, author, company and a project summary, as shown in Fig. 7.

The second window, entitled Production, refers to the data for each product component in the Production stage, including a general description of each component production, the number of components for each type, material composition, mass, manufacturing process and the quantity of processed components, as illustrated in Fig. 8. At this stage, it is also possible to introduce the volume data for 
Fig. 7 Life cycle window: reference data project

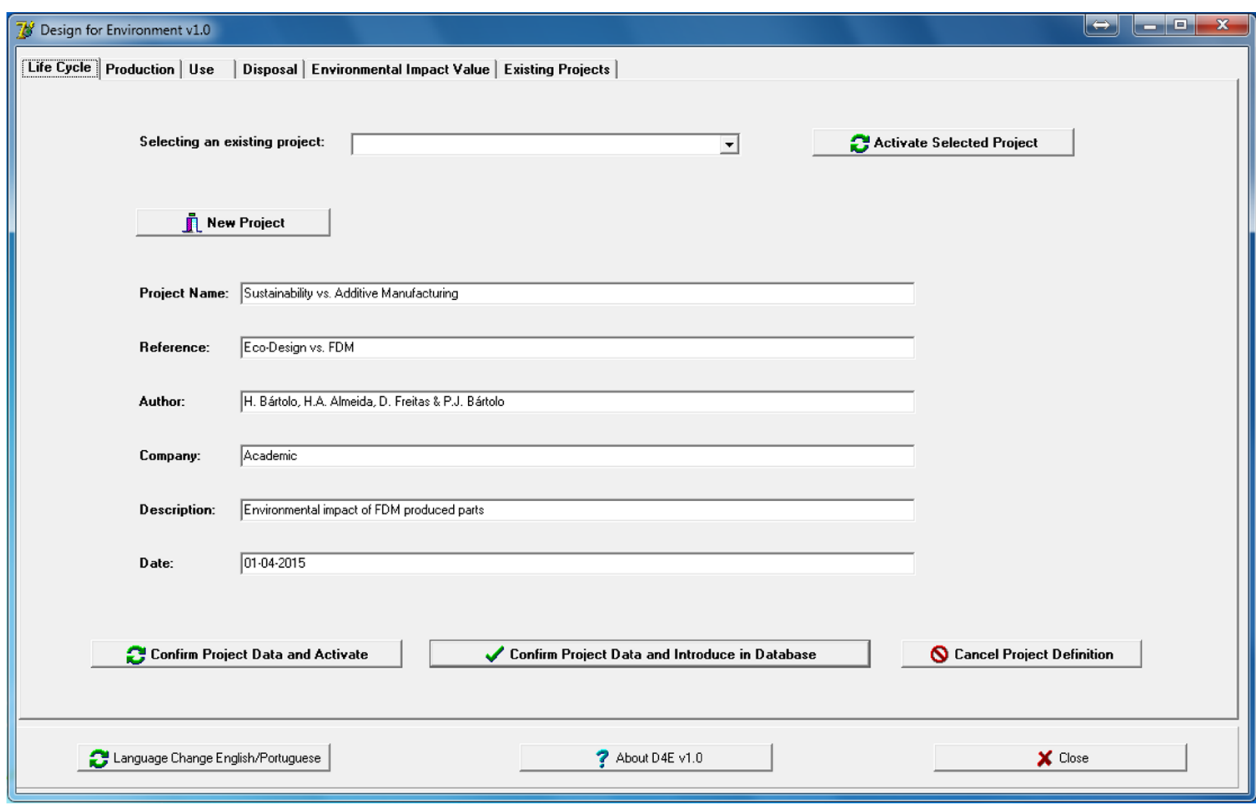

Fig. 8 Production Window: definition of the production stage

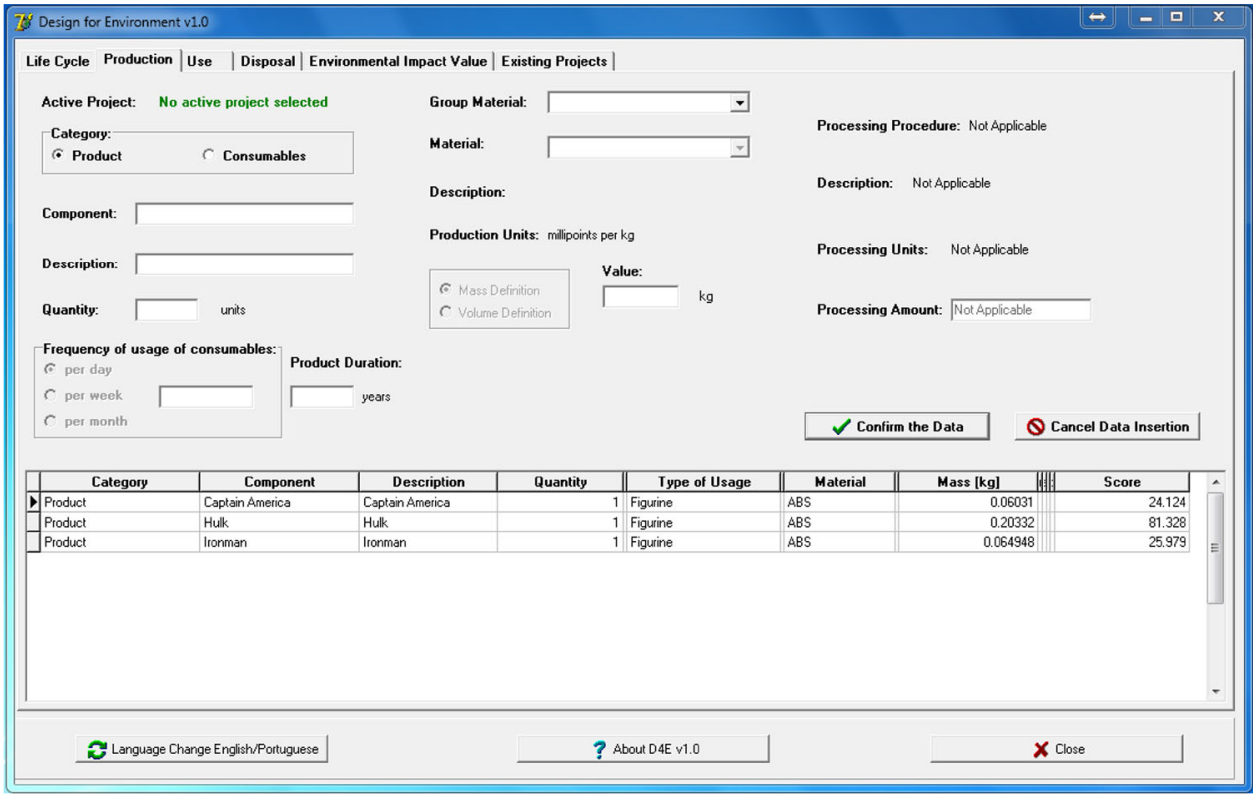

each product component, which can be determined by either the 3D product analysis, or the measure of the mass of each component using an analytical balance. The data will then be added to the respective table in this window.

The third window entitled Use (Fig. 9), refers to the use stage including the consumed energy or/and the use transport regarding the distribution phase. Transport data refers to the transport type and distance.

The disposal window refers to the final destination of each product component (Fig. 10). In this step, users can simulate the final destination of each product component including recycling, incineration, landfill and waste. The sum of the percentage for each component must be equal to one hundred per cent $(\Sigma=100 \%)$, no matter the values obtained for each disposal proportion.

After introducing all the data in the previous windows, it is then possible to calculate the environmental impact for each step of the product's lifecycle through the visualization of charts (Fig. 11).

The environmental impact value window displays four chart analyses of the environmental impacts regarding a product: production, use and disposal stages for each product component. The final value of the product's environmental impact will then be the sum of the 
Fig. 9 Use window: definition of the use stage

Fig. 10 Disposal window: definition of the disposal stage
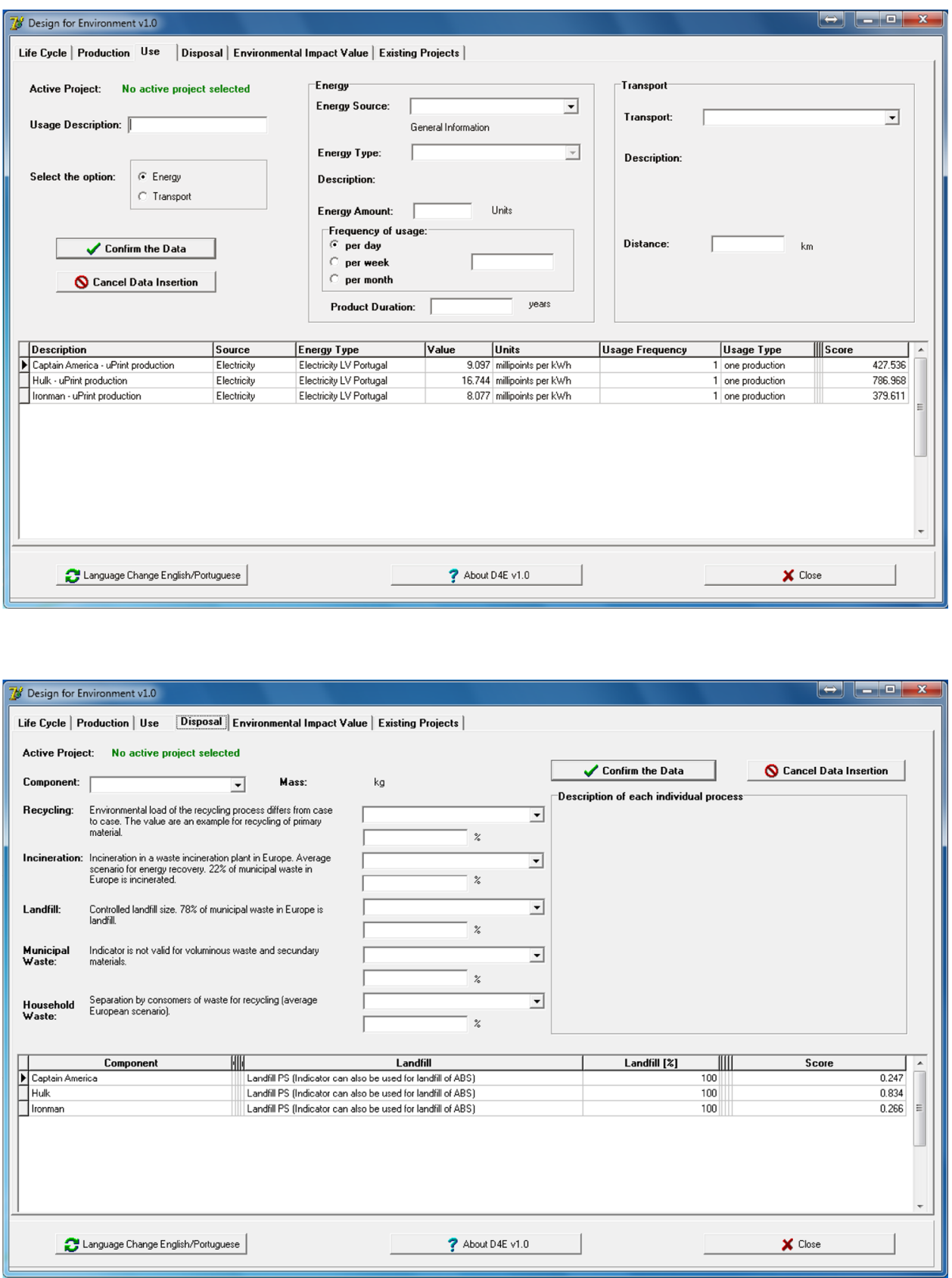

environmental impact values, obtained from the stages of production, use and disposal.

\section{Case study}

With the aid of the D4E tool, the LCA of FDM parts is obtained as a function of the angular position of the building orientation from a laying down to a standing position, on both back to lateral positioning, alongside with the three interior part filling options, in order to determine the product's environmental impact. In this particular study, three figurines of super heroes were considered for the evaluation of the FDM's environmental impact, namely Captain America, Hulk and Ironman. Figure 12 illustrates the three super hero figurines and their dimensions. In order to perform a comparison between the three super heroes, they were all scaled to a height of $150 \mathrm{~mm}$. This research work is based on the production simulation data from the uPrint software since it is capable of presenting all the necessary data without producing the high number of produced physical models necessary to undergo this study. 
Fig. 11 Example of environmental impact value window

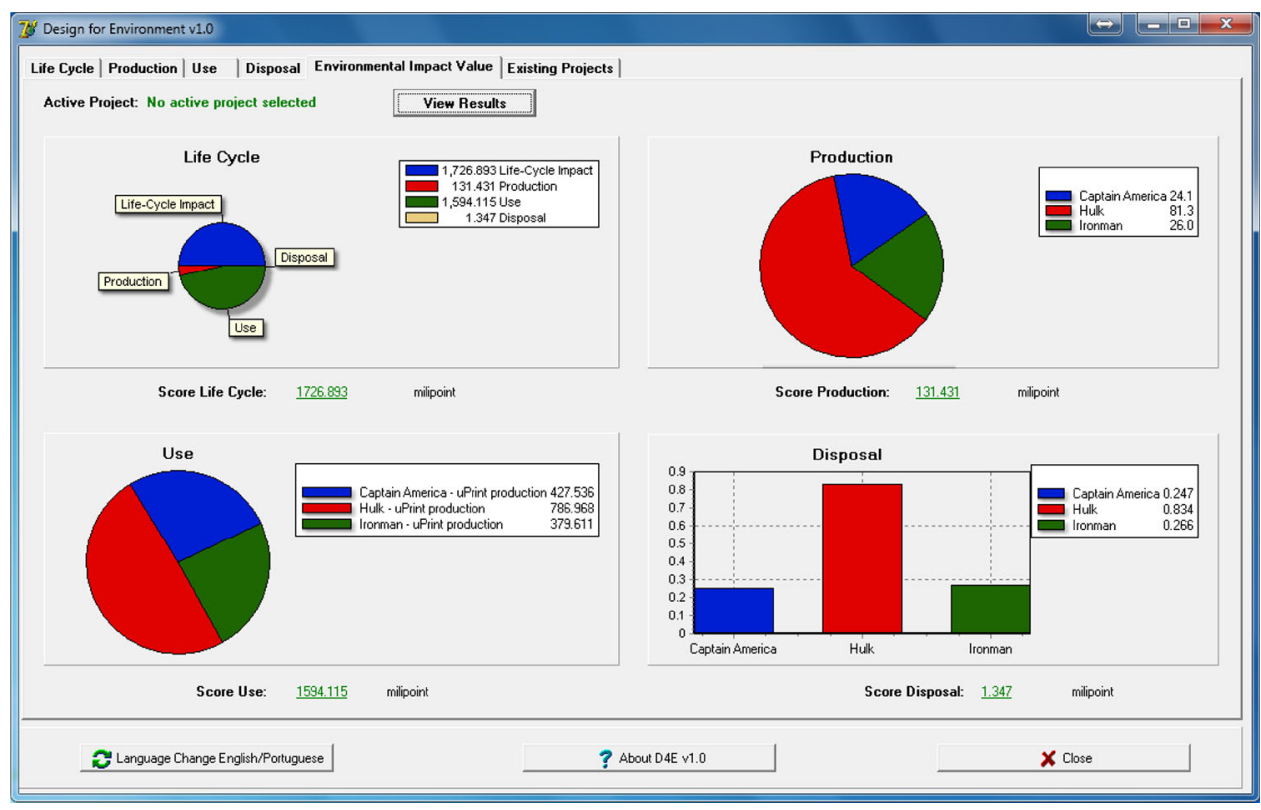

Fig. 12 The three super heroes considered in this study and their dimensions: a Captain America, b Hulk and c Ironman

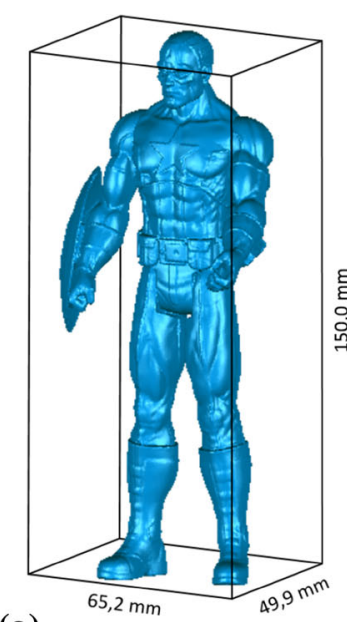

(a)

(b)

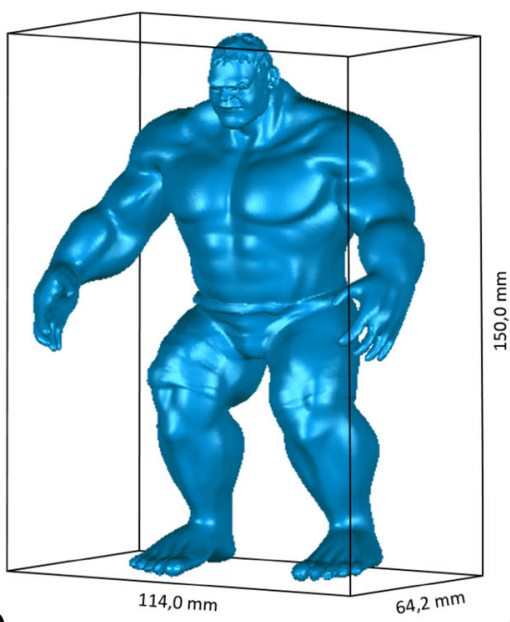

(c)

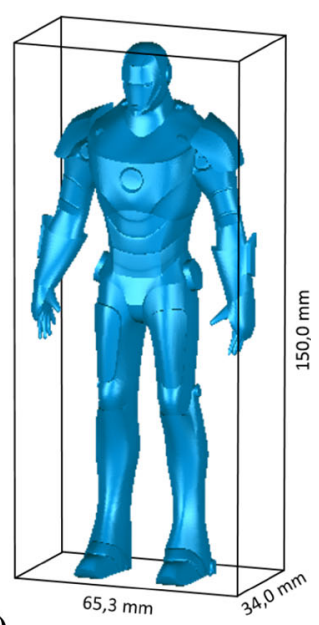

therefore presenting itself as an ideal material for functional prototyping through direct digital manufacturing. Regarding the support material, the uPrint system uses a washable release material. In this case, the environmental impact value of the release material was not considered because there is no eco-indicator value for the given material. The system supplier only mentions that the support material has an Ecoworks $\mathrm{pH}$ level of 10, and that it meets most worldwide wastewater requirements. Nevertheless, during the production, the energy consumption encompasses both the extrusion of the model and the release material.

Data regarding the types and weight of material for each product is essential to evaluate each life cycle, as each material and manufacturing process is associated with an eco-indicator value. The first step for the environmental 
Fig. 13 Part orientation options for construction: a lateral laydown to standing position and $\mathbf{b}$ back laydown to standing position

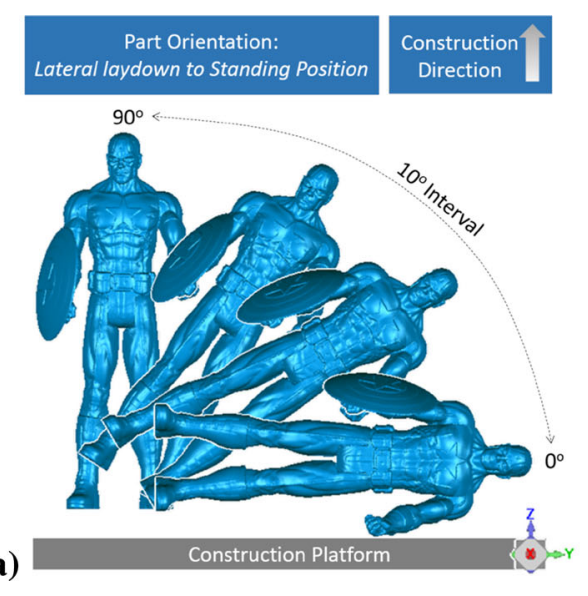

(a)
Construction

Direction (b)
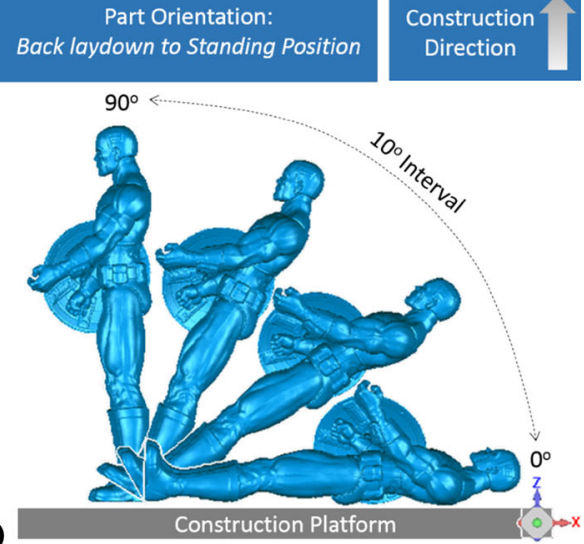

impact analysis was the quantification of the amount of ABS material needed for the production of each one of the three super hero figurines. The time was also quantified, so that the energy consumption could be calculated. Another issue taken into account regards the part's orientation during the production process. In this case, two fabrication orientations were considered, as illustrated in Fig. 13. Each figurine was positioned either on its back or its lateral position, corresponding to the $0^{\circ}$ position. Then each figurine was rotated with a $10^{\circ}$ interval until it reached its standing position, corresponding to the $90^{\circ}$ position.

The Hulk figurine is the biggest one of the three, while Ironman and Captain America have approximately the same volume. In order to determine the deviations of the material volume for each position and Angular Orientation, the ideal volume was determined based on the STL.

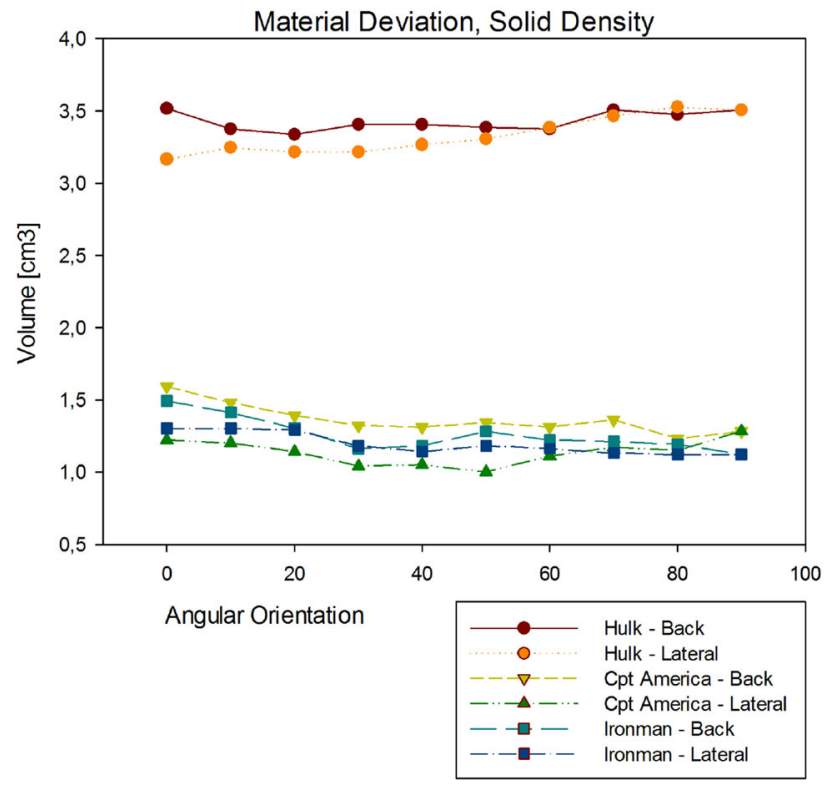

Fig. 14 Material deviation for a solid density production of the three figurines
According to the STL files, Hulk, Ironman and Captain America have the volume of 191.984, 60.958 and $56.398 \mathrm{~cm}^{3}$ respectively. Then the deviations of the material volume were calculated in comparison with the material volume predictions for each figurine for each position and Angular Orientation (Fig. 14).

Comparing the Solid Density production of the two printing positions (back and lateral) while changing the Angular Orientation, it is possible to observe that for the three figurines, the back position consumes more material in order to build the figurines. The angular orientation where both printing positions have an equivalent consumption of material is situated between $60^{\circ}$ and $80^{\circ}$ for the Hulk and Ironman figurines. Captain America due to his shield on his right arm, only presents an equivalent consumption between printing positions at $80^{\circ}$. Taking into account the angular orientation, it is possible to observe that the $0^{\circ}$ has a higher consumption of material in the back position than in the lateral position. In the lateral position, the angular orientation that consumes more material varies between $10^{\circ}$ and $20^{\circ}$ for Captain America and Ironman and between $70^{\circ}$ and $80^{\circ}$ for the Hulk.

In terms of production time for the high density printing, it is possible to observe (Fig. 15) that the lateral position has higher values for all three figurines, with exception between $50^{\circ}$ and $80^{\circ}$ for Ironman. Comparing the angular orientation, it is possible to observe that for all three figurines, the range between $70^{\circ}$ and $80^{\circ}$ presents the highest production times. Until an angular orientation of $50^{\circ}$, the production time increases significantly, continuing to increase at a lower rate until $70^{\circ}$ approximately, afterwards decreasing slightly between $80^{\circ}$ and $90^{\circ}$. Regarding the number of construction layers during production, the behaviour is also similar. Figure 16 illustrates layers during production, the number of layers, until an angular orientation of $50^{\circ}$, the number of construction layers increases significantly, continuing to increase at a lower rate until $70^{\circ}$ approximately, afterwards decreasing slightly between 


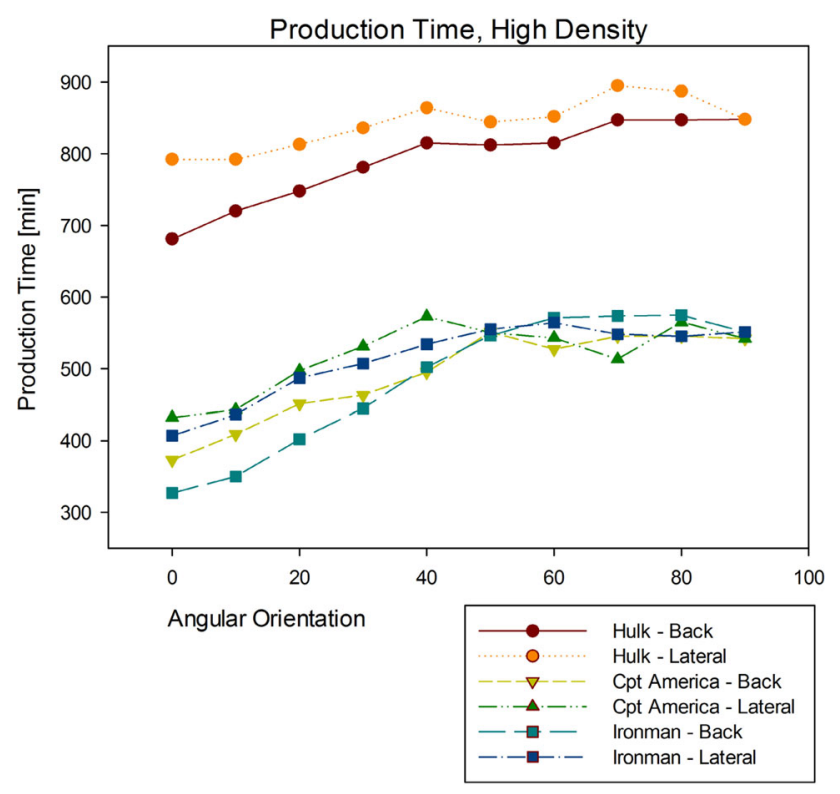

Fig. 15 Production time for a high density production of the three figurines

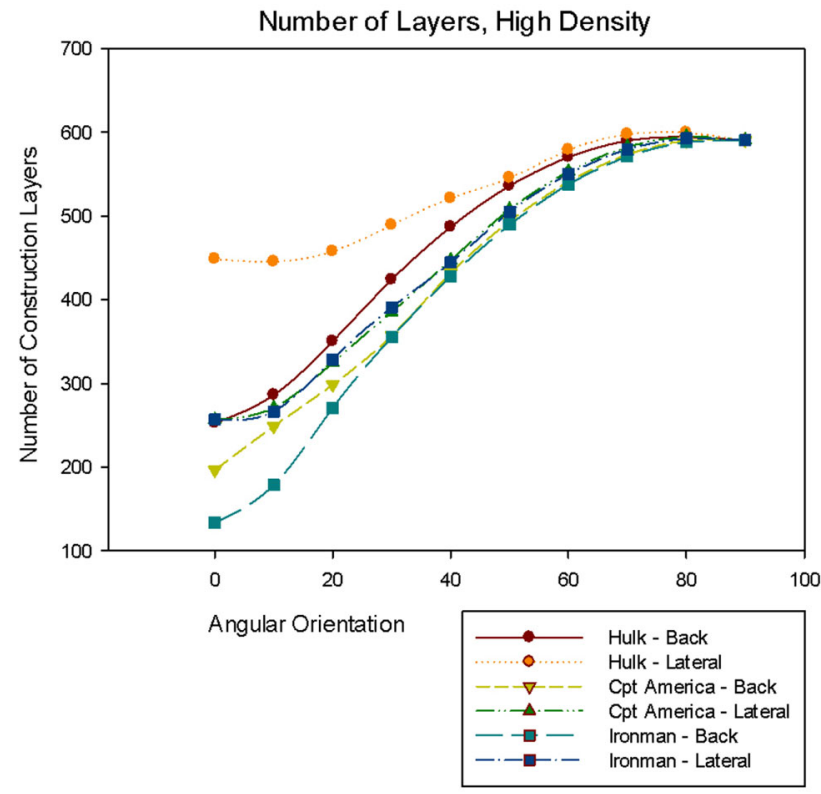

Fig. 16 Number of construction layers for a high density production of the three figurines

$80^{\circ}$ and $90^{\circ}$. By analysing both figures, it is possible to observe that the production time is highly dependent on the number of construction layers during production.

Analysing the three printing densities in terms of Production Time for the Hulk figurine, it is possible to assess (Fig. 17) that the high density printing for the lateral position presents the highest production time, whereas the lowest production time, is the low density printing in the back position. The other two figurines present a similar

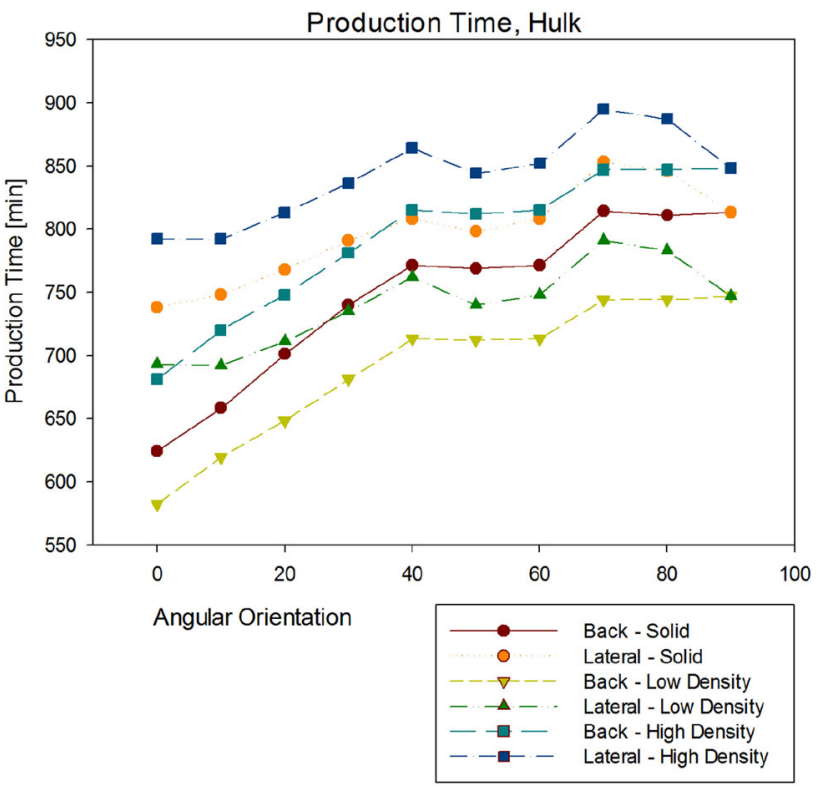

Fig. 17 Production time for the Hulk figurine

behaviour. It is also possible to note that the production time increases considerably until $40^{\circ}$ for all the production combinations (position and density) and after that increases slightly till reaching $70^{\circ}$ for the back printing position. As for the lateral position, it is possible to observe a slight decrease at $50^{\circ}$ for all the production densities increasing afterwards until $90^{\circ}$.

The data was inserted into the D4E tool considering the following aspects:

- In the production stage, the support material consumption was neglected.

- Due to the functionality of the products, there was no energy expenditure during the life cycle for the use stage, although energy consumption was considered for the uPrint system during the production.

- Two possible options regarding the product's final destination (disposal) were considered: (1) solution 1the components were incinerated, and (2) solution 2 the components were sent to landfill.

Based on these considerations, three scenarios were considered for the parts and 1 for the uPrint system:

- The first scenario only considers the ABS material impact and its amount without considering any end-oflife/disposal options. Currently, there are no ecoindicators for AM systems, so no processing ecoindicator was considered.

- The second scenario considers the ABS material and a $100 \%$ end-of-life incineration.

- The third scenario considers the ABS material and a $100 \%$ end-of-life landfill. 


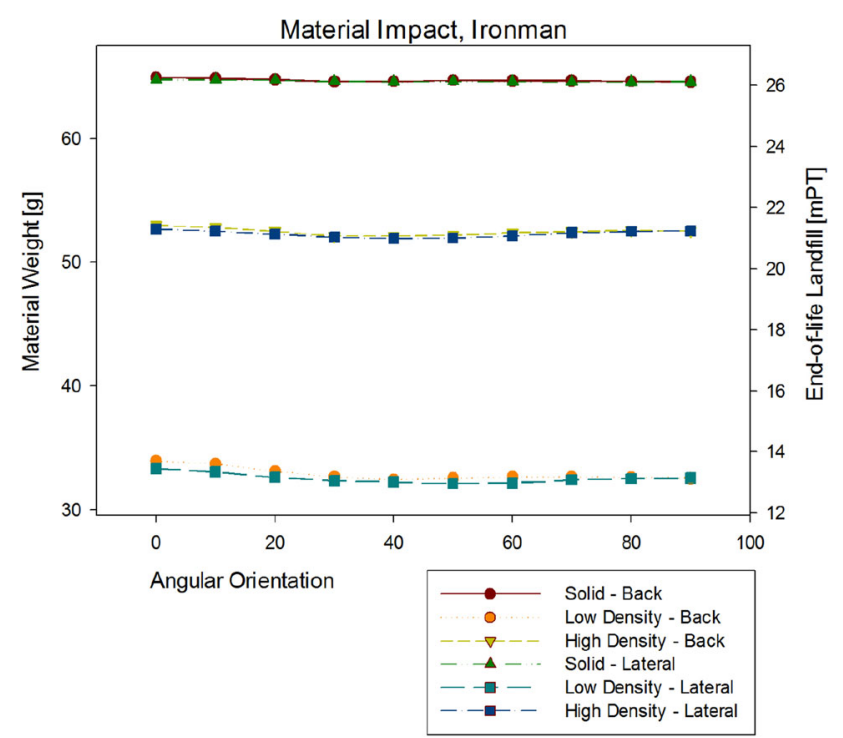

Fig. 18 Environmental material and landfill end-of-life for Ironman

- The fourth scenario considers the environmental impact of the uPrint energy consumption during the production process.

Next, it was possible to visualize the data charts and environmental impact results for each option through the D4E window, regarding the product (material, material and disposal) and the equipment (usage).

The main purpose of this study is to assess the sustainability impact of the printed objects accordingly to their printing positions (angular orientation and position). When observing Fig. 18 it is possible to refer that the Ironman figurine printed in solid density has a higher impact regarding the amount of used material, since it's a solid model. In accordance, the low density model has a lower material impact. The Ironman in a solid density has a little more than $65 \mathrm{~g}$ which gives a sustainable impact when using the Landfill option as an end-of-life solution of approximately $26 \mathrm{mPT}$. Comparing the two used positions of rotation, the back and lateral, it is possible to refer that the back position has a higher impact for the three printing densities. This can be seen more distinctively when printing in low density.

Comparing the impact of the three disposable solutions, i.e., (1) without end-of-life; (2) incineration; and (3) landfill; it is possible to observe (Fig. 19) that the landfill has a higher impact value and the Incineration the lowest, being the difference between them approximately of 0,6 $\mathrm{mPT}$. Another visible aspect, it is that for all the disposable solutions, the back printing position has a higher impact value than the lateral position.

When analysing Fig. 19, it is also possible to observe that the angular orientation with a higher environmental impact situates at $0^{\circ}$ for both positions, even if the back

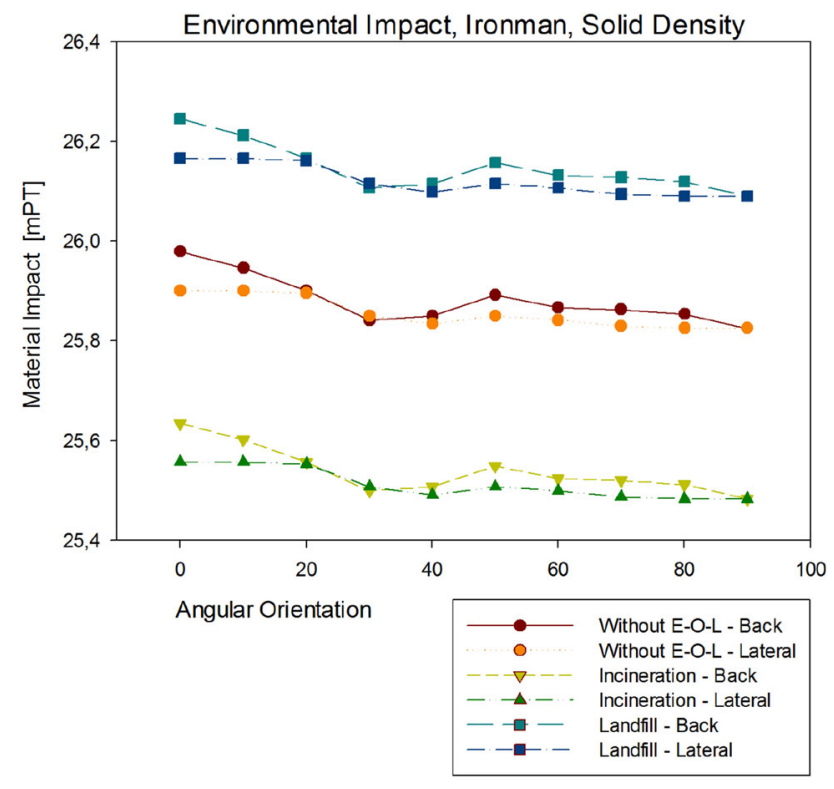

Fig. 19 Environmental material impact value for all three end-of-life solutions for Ironman

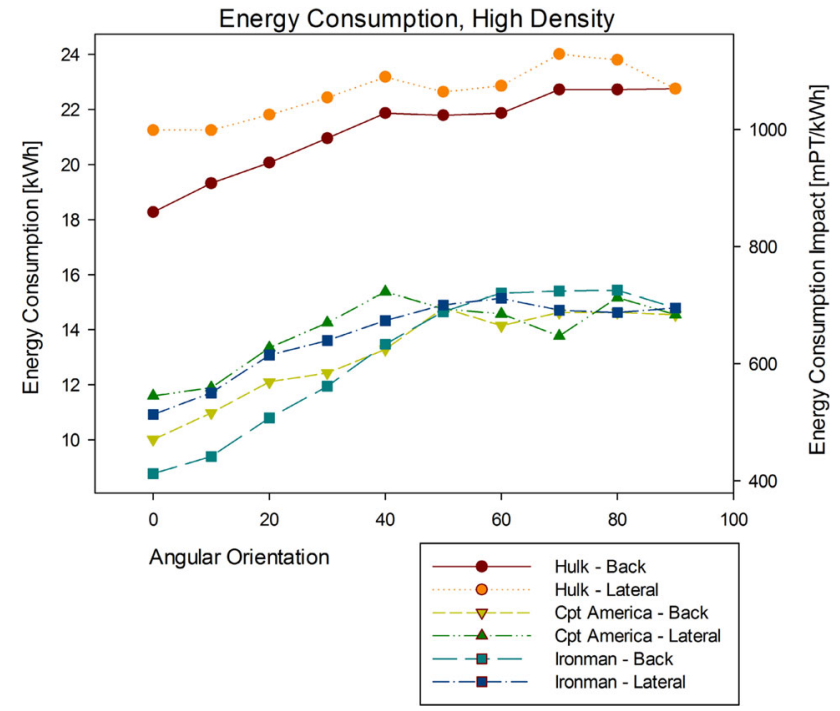

Fig. 20 Environmental energy consumption impact value

position it is slightly higher than the lateral position. For both positions, the angle with the lowest impact value is the $90^{\circ}$ that corresponds to the standing position of the figurines.

Regarding energy consumption of the high density production (the printing option that presents higher production times and energy consumptions), it is possible to observe that the lateral position consumes more energy and presents the highest impact value at $70^{\circ}$ for the Hulk, and for the Captain America it is at $60^{\circ}$ and Ironman at $80^{\circ}$ (Fig. 20). The lowest energy 
consumption is when the object contains lesser layers, in this case, at $0^{\circ}$ in the back printing position, a tendency seen in all three figurines.

The part's orientation is critical regarding the energy consumption during the production process, in spite of the amount of consumed material presents no significant changes. Depending on the type of interior model (solid, high or low density) used, the solid filling one has the highest environmental impact in terms of material impact, while the high density presents higher impact values in terms of energy consumption. Either if the product's aim is decorative or conceptual, it is important not only to consider the amount of material used in the process but also the strategy used for producing the product. The amount of material used is also critical regarding the possible end-oflife disposal scenarios.

This research work also enabled to make a comparison on the environmental impact of the product's material and the extrusion's system energy consumption. In either of the case scenarios, to minimize the environmental impact, it is essential to shorten the time the extrusion system is on without any production, as well reducing the amount of productions, so that the heating and machine warm-up may be more diluted between productions, minimizing the environmental energy impact. In this particular case study, the material's environmental impact corresponds to an average value of 5.8, 3 and $3.3 \%$ of the global environmental impact value (material and energy) for Hulk, Captain America and Ironman respectively.

\section{Conclusions}

Additive manufacturing technologies are being used as an economical and viable alternative for fabricating complex production parts in many industrial sectors. As public interest in AM grows, its usage for the production of final parts is ever more used, which can support a drive to sustainability towards a more sustainable manufacturing scenario.

There are many concerns regarding parts' quality, production time, cost, etc., but fewer regarding the sustainability of the process. The proposed D4E computational tool allows obtaining data about a product's environmental impact, for each life cycle stage, which can contribute to optimize the design product and minimize its environmental impacts along the life cycle. It also provides a variety of charts enabling data visualization and analysis, showing product's environmental impact. This system is a fast and efficient way to analyse the whole life cycle of real products, and virtual models, generating better solutions for production, use and final disposal. D4E system can be a step forward to optimize additive systems, turning the additive process into a more sustainable one regarding analysis and optimization of a products' life cycle. This tool also aims at influencing decision-making by creating products to be recycled and reused, thereby contributing to the reduction of the impacts and costs associated with all stages of a product's development.

This research work demonstrates that the part's orientation is critical regarding the energy consumption during the production process, in spite of the amount of consumed material presenting very slim deviations. The figurines in the upright position, present lower material consumption values and higher energy consumption values, while in the laying down position, the figurines present higher material consumption values and lower energy consumption values. Depending on the type of interior model used (solid, high or low density), the solid filling one has the highest material environmental impact, while the high density presents the highest energy environmental impact. Regarding environmental impact, either one chooses to use more material and consuming less energy or one chooses to use less material and consuming more energy. Either if the product's aim is decorative or conceptual, it is important not only to consider the amount of material used in the process but also the strategy used for producing the product. The amount of material used is also critical regarding the possible end-of-life disposal scenarios. This work also enabled to make a comparison on the environmental impact of the product's material and the extrusion's system energy consumption. In either of the case scenarios, to minimize the energy environmental impact, it is essential to shorten the time the extrusion system is on without any production, as well reducing the amount of productions, diluting the pre-heating between productions, minimizing the energy environmental impact.

\section{References}

1. Ajoku U, Saleh N, Hopkinson N, Hague R, Poonjolai E (2006) Investigating mechanical anisotropy and end-of vector effect in laser-sintered nylon parts. Proc Inst Mech Eng Part B J Eng Manuf 220(7):1077-1086

2. Alexander P, Allen S, Dutta D (1998) Part orientation and build cost determination in layered manufacturing. Comput Aided Des 30(5):343-356

3. Allen S, Dutta D (1995) On the computation of part orientation using support structures in layered manufacturing. J Des Manuf 5:153-162

4. Ang KC, Leong KF, Chua CK, Chandrasekaran M (2006) Investigation of the mechanical properties and porosity relationships in fused deposition modelling-fabricated porous structures. Rapid Prototyp J 12(2):100-105

5. Anitha R, Arunachalam S, Radhakrishnan P (2001) Critical parameters influencing the quality of prototypes in fused deposition modelling. J Mater Process Technol 118:2-5 
6. Armillotta A (2006) Assessment of surface quality on textured FDM prototypes. Rapid Prototyp J 12(1):35-41

7. Atkins (2007) ATKINS Manufacturing a Low Carbon Footprint, ATKINS project report. http://www.atkins-project.com/pdf/ ATKINSfeasibilitystudy.pdf. Accessed April 2015

8. Bártolo PJ, Almeida HA, Laoui T (2009) Rapid prototyping and manufacturing for tissue engineering scaffolds. Comput Appl Technol 36(1):1-9

9. Beaman JJ, Barlow JW, Bourell DL, Crawford RH, Marcus HL, McAlea KP (1997) Solid freeform fabrication: a new direction in manufacturing. Kluwer Academic, Boston

10. Berry M (2004) The importance of sustainable development. Columbia Spectator, Canada

11. Chockalingam K, Jawahar N, Ramanathan KN, Banerjee PS (2005) Optimization of stereolithography process parameters for part strength using design of experiments. Int $\mathbf{J}$ Adv Manuf Technol 29(1-2):79-88

12. Chua CK, Fai LK (2000) Rapid prototyping: principles and applications in manufacturing. World Scientific Publishing, Singapore

13. Chua CK, Leong KF, Lim CS (2003) Rapid prototyping: principles and applications in manufacturing, 2nd edn. World Scientific Publishing, Singapore

14. Crump SS (1989) Apparatus and method for creating three-dimensional objects. US Pat. 5121329

15. Durgun I, Ertan R (2014) Experimental investigation of FDM process for improvement of mechanical properties and production cost. Rapid Prototyp J 20:228-235

16. Equbal A, Ohdar RK, Mahapatra SS (2011) Prediction of dimensional accuracy in fused deposition modelling: a fuzzy logic approach. Int J Prod Qual Manag 7(1):22-43

17. Finnvedena G, Hauschildb M, Ekvallc T, Guinée J, Heijungs R, Hellweg S, Koehler A, Pennington D, Suh S (2009) Recent developments in life cycle. J Environ Manage 92(1):1-21

18. Gibson I (2011) Is additive manufacturing a sustainable technology? In: Bártolo $\mathrm{H}$ et al (eds) Proceedings of SIM2011 sustainable intelligent manufacturing. IST Press, Lisbon, pp 583-589

19. Gibson I, Rosen D, Stucker B (2015) Additive manufacturing technologies-3D printing, rapid prototyping and direct digital manufacturing, 2nd edn. Springer, New York

20. Gibson I, Shi D (1997) Material properties and fabrication parameters in selective laser sintering process. Rapid Prototyp J 3:129-136

21. Goedkoop M, Spriensama R (2001) The eco-indicator 99: a damage oriented method for life cycle impact assessment. Methodology Report, Netherlands

22. Hague R (2005) Unlocking the design potential of rapid manufacturing. In: Hopkinson $\mathrm{N}$ et al (eds) Rapid manufacturing: an industrial revolution for the digital age. Wiley, Chichester

23. Hascoet JY, Marya S, Marya M, Singh V (2014) Materials science challenges in the additive manufacturing of industrial parts. In: Kai CC et al (eds) Proceedings of the 1st international conference on progress in additive manufacturing (ProAM2014). Research Publishing Services, Singapore, pp 133-138

24. Hopkinson N, Hague RJM, Dickens PM (2006) Rapid manufacturing - an industrial revolution for the digital age. Wiley, England

25. Howarth G, Hadfield M (2006) A sustainable product design model. Mater Des 27(10):1128-1133

26. Kotliniski J (2014) Mechanical properties of commercial rapid prototyping materials. Rapid Prototyp J 20(6):499-510

27. Kumar GP, Regalla SP (2011) Optimization of support material and build time in fused deposition modeling (FDM). Appl Mech Mater 110-116:2245-2251
28. Lee CS, Kim SG, Kim HJ, Ahn SH (2007) Measurement of anisotropic compressive strength of rapid prototyping parts. J Mater Process Technol 187-188:627-630

29. Lee K (1999) Principles of the CAD/CAM/CAE systems. Addison Wesley Longman, Chicago

30. Lofthouse V (2006) Ecodesign tools for designers: defining the requirements. J Clean Prod 14(15-16):1386-1395

31. Luo Y, Ji Z, Leu MC, Caudill R (1999) Environmental performance analysis of solid freeform fabrication processes. In: Proceedings of the 1999 IEEE international symposium on electronics and the environment (ISEE-1999), IEEE

32. Majewski C, Hopkinson N (2011) Effect of section thickness and build orientation on tensile properties and material characteristics of laser sintered nylon-12 parts. Rapid Prototyp J 17(3):176-180

33. Morrow WR, Qi H, Kim I, Mazumder J, Skerlos SJ (2007) Environmental aspects of laser-based and conventional tool and die manufacturing. J Clean Prod 15:932-943

34. Onuh SO, Hon KKB (1998) Optimising build parameters for improved surface finish in stereolithography. Int J Mach Tools Manuf 38(4):329-342

35. Pham DT, Demov SS (2001) Rapid manufacturing: the technologies and applications of rapid prototyping and rapid tooling. Springer, London

36. Quintana R, Choi JW, Puebla K, Wicker R (2010) Effects of build orientation on tensile strength for stereolithography-manufactured ASTM D-638 type I specimens. Int J Adv Manuf Technol 46:201-215

37. Reeves P (2009) Additive Manufacturing - a supply chain wide response to economic uncertainty and environmental sustainability. In: International conference on industrial tools and material processing technologies, Ljubljana, Slovenia

38. Rosen D (2014) What are the principles for design for additive manufacturing? In: Kai CC et al (eds) Proceedings of the 1st international conference on progress in additive manufacturing (Pro-AM2014). Research Publishing Services, Singapore, pp 85-90

39. Santos AL (2011) Eco-design computational tool, based on ecoindicators. MSc Thesis Polytechnic Institute of Leiria, Portugal

40. Santos AL, Almeida H, Bártolo H, Bártolo P (2011) Integrated strategy for sustainable product development. In: Bártolo PJ et al (eds) Innovative research in virtual and physical prototyping. CRC Press, London, pp 807-812

41. Saqib S, Urbanic J (2012) An experimental study to determine geometric and dimensional accuracy impact factors for fused deposition modelled parts. In: ElMaraghy (ed) Enabling manufacturing competitiveness and economic sustainability. Springer, Berlin, pp 293-298

42. Sood AK, Ohdar RK, Mahapatra SS (2009) Improving dimensional accuracy of fused deposition modelling processed part using grey Taguchi method. Mater Des 30(10):4243-4252

43. Sood AK, Ohdar RK, Mahapatra SS (2010) Parametric appraisal of mechanical property of fused deposition modelling processed parts. Mater Des 31(1):287-295

44. Sood AK, Ohdar RK, Mahapatra SS (2012) Experimental investigation and empirical modelling of FDM process for compressive strength improvement. J Adv Res 3(1):81-90

45. Sreenivasan R, Goel A, Bourell DL (2010) Sustainability issues in laser-based additive manufacturing, LANE 2010. Phys Procedia 5:81-90

46. Stratasys, Inc (2010) uPrint $^{\circledR}$ and uPrint ${ }^{\circledR}$ plus personal 3D printers user guide. Stratasys, Inc, Eden Prairie

47. Thrimurthulu K, Pandey PM, Reddy NV (2004) Optimum part deposition orientation in fused deposition modeling. Int $\mathbf{J}$ Mach Tools Manuf 44:585-594 
48. Vijay I, Chockalingam K, Kailasanathan C, Sivabharathy M (2014) Optimization of surface roughness in selective laser sintered stainless steel parts. Int J Chem Tech Res 6(5):2993-2999

49. Vijay P, Danaiah PD, Rajesh KV (2012) Critical parameters effecting the rapid prototyping surface finish. J Mech Eng Autom 1(1): $17-20$
50. Volpato N, Foggiatto JA, Schwarz DC (2014) The influence of support base on FDM accuracy in Z. Rapid Prototyp J 20:2

51. Zhang Y, Bernard A (2013) Using AM feature and multi-attribute decision making to orientate part in additive manufacturing. In: Bártolo PJ et al (eds) High value manufacturing. CRC Press, London, pp 411-416 